\title{
The meaning of mathematics instruction in multilingual classrooms: analyzing the importance of responsibility for learning
}

\author{
Åse Hansson
}

Published online: 12 February 2012

(C) The Author(s) 2012. This article is published with open access at Springerlink.com

\begin{abstract}
In the multilingual mathematics classroom, the assignment for teachers to scaffold students by means of instruction and guidance in order to facilitate language progress and learning for all is often emphasized. In Sweden, where mathematics education is characterized by a low level of teacher responsibility for students' performance, this responsibility is in part passed on to students. However, research investigating the complexity of relations between mathematics teaching and learning in multilingual classrooms, as well as effect studies of mathematics teaching, often take the existence of teachers' responsibility for offering specific content activities for granted. This study investigates the relations between different aspects of responsibility in mathematics teaching and students' performance in the multilingual mathematics classroom. The relationship between different group compositions and how the responsibility is expressed is also investigated. Multilevel structural equation models using TIMSS 2003 data identified a substantial positive influence on mathematics achievement of teachers taking responsibility for students' learning processes by organizing and offering a learning environment where the teacher actively and openly supports the students in their mathematics learning, and where the students also are active and learn mathematics themselves. A correlation was also revealed between group composition, in terms of students' social and linguistic background, and how mathematics teaching was performed. This relationship indicates pedagogical segregation in Swedish mathematics education by teachers taking less responsibility for students' learning processes in classes with a high proportion of students born abroad or a high proportion of students with low socio-economic status.
\end{abstract}

Keywords Mathematics teaching - Second language learners · Responsibility for learning · Pedagogical segregation $\cdot$ Hierarchical modelling with latent variables

\footnotetext{
A. Hansson ( $\square)$

Department of Pedagogical, Curricular and Professional Studies, University of Gothenburg, Box 300,

40530 Gothenburg, Sweden

e-mail: ase.hansson@ped.gu.se
} 


\section{Introduction}

In Sweden, mathematics teaching has, for some time, been characterized by the fact that students have to take a major responsibility for their own learning processes (Carlgren, Klette, Myrdal, Schnack, \& Simola, 2006; Johansson, 2006; Kling Sackerud, 2009). The teacher's commitment and responsibility has, through the dominance of this kind of instruction, "students' independent work", decreased, and mathematics teaching has changed toward less interaction and cooperative learning approaches (Skolverket, 2009; Vinterek, 2006; Österlind, 1998).

A characteristic of mathematics teaching, thus, is how the responsibility for students' learning processes is framed. The assignment to take responsibility for students' learning processes is about offering a learning environment that supports students' mathematics learning. For teachers, this could be enacted through their instruction and guidance of students in order to facilitate learning for all. If they do not take responsibility for creating such an environment, the students can come to work at their own pace in the textbook, and the learning objectives can come to be both formulated and fulfilled by students themselves. In order to describe mathematics teaching from this perspective, a model is required that highlights dimensions of the responsibility for the learning processes hypothesized to be important for student's construction of knowledge in mathematics. In a prior study (Hansson, 2010), a model was developed comprising three theoretically based dimensions that identify and describe such responsibility, namely: Teacher Activity, Student Activity and a dimension that illustrates that the Mathematics Content is highlighted as an object of teaching, see Fig. 3 in Section 3.2.4.

The theoretical starting points of the model draw on Vygotskij's and Brousseau's perspectives on teachers' engagement and students' construction of knowledge (Brousseau, 1997; Vygotskij, 1978). Based on these theories, learning is viewed as a process where more complex structures of knowledge can be attained through interaction with other people and the teacher's engagement is considered to be a central requirement for students' learning processes. Vygotskij's theory focuses on the mechanism of developing skills and strategies, and the Zone of Proximal Development (ZDP) is the concept that explains this mechanism: "the distance between the actual developmental level as determined by independent problem solving and the level of potential development as determined through problem solving under adult guidance, or in collaboration with more capable peers" (Vygotskij, 1978, p. 86). With the scaffolding of the teacher (Bruner, 1960), students can widen and deepen their knowledge within their ZDP, but they are assumed to be active and to construct their knowledge themselves. Brousseau's theory also regards the learning environment, with teachers scaffolding students and offering valid conditions for learning, as important for students' own construction of their knowledge. The teacher has, in line with Brousseau's theory, the responsibility for creating a-didactical learning situations in which the teacher does not make known to the students his/her intention regarding the knowledge students have to construct. Nevertheless, the teacher is still responsible for scaffolding students through the a-didactical situations. Teachers cannot be said to have the power to make the students learn, which is the students' responsibility, but they have the responsibility for scaffolding students in their own learning processes and for offering conditions for students to access the knowledge. The institutionalization of knowledge (Brousseau, 1997) also aims to make knowledge socially and culturally acceptable, which means that it not only is individual, but that it also can be used in other situations outside the school context.

By considering mathematics teaching from these theoretical starting points, it was possible in the previous study (Hansson, 2010) to distinguish different dimensions of 
mathematics teaching, which the teacher is responsible for organizing and providing. These dimensions constituted the multidimensional construct REsponsibility for students' Learning process (REL), hypothesized to be important for students' possibilities to perform in mathematics. The first dimension was represented by the factor Teacher Activity. This factor was hypothesized to concern teacher's responsibility for actively and openly supporting students in their mathematics learning by, for example, highlighting and explaining the mathematics content, questioning and conversing with students, and organizing instruction so as to create conditions for interaction and various social activities. The second dimension was hypothesized to be the Student Activity, which concerns the teacher's responsibility for handing over responsibility to the students for their own construction of knowledge by, for example, encouraging them to reflect on and reason about mathematical problems. Finally, a third dimension, Mathematics Content, was hypothesized to be the teacher's responsibility for highlighting the content relevant to the grade as the object of teaching. To validate the measurement model of REL, a multilevel confirmatory factor analysis with latent variables was used as the method of analysis, and the empirical data set used was TIMSS 2003, mathematics eighth grade. The factors Teacher and Student Activity were indicated in the model by observed variables from both the student and teacher questionnaires, and the factor Mathematics Content was indicated by observed variables from the student questionnaire. In contrast to more traditional models for mathematics instruction, the model developed in the previous study provided a conceptual tool for simultaneously focusing on different dimensions of REL when analyzing classroom practices, and this tool has been used in the present study.

In Sweden, the increasing individualization of mathematics education, with reduced teacher responsibility for the learning processes as a consequence, has been accompanied by declining mathematics results. In recent decades, the means have decreased, and the variation between students and classes has increased, which, taken together, motivates an investigation of the relationship between responsibility for students' learning process and mathematics results. There are also other changes likely to be related to these declines in results. Multilingualism as a result of demographic changes through continuous international migration has, for example, become apparent in many mathematics classrooms (Coleman, 2006), and students with a foreign background are further shown to be less successful than their Swedish classmates (Skolverket, 2009). Depending on second language learners' need for scaffolding to make progress in their linguistic and mathematical skills (Cummins, 1984; Gibbons, 2002; Vygotskij, 1978), learning mathematics in a second language is hypothesized to be related to the REL approach chosen. The importance of teachers taking responsibility for enabling students' development of both language and mathematics skills is supported by previous research in this field. Howie (2003), for example, has shown that it is essential for multilingual students' opportunities to learn mathematics that they have high competencies in the language of instruction. By using TIMSS data for South Africa, the author shows that students' proficiency in the test language is a strong predictor of their success in mathematics. However, problems related to mathematics instruction and language do not only apply to second language learners, but also to students separated for social reasons. Some students could be said to use a simpler, constrained, language bound to specific contexts (Bernstein, 2000), or their lack of linguistic capital could be said to make them less familiar with the language supportive of mathematics progress (Bourdieu, 1984). Irrespective of cause, linguistic or social, students' lack of linguistic ability would be manifested in the mathematics classroom and possibly exacerbated by the type of mathematics tasks students will work with (Cooper \& Dunne, 2000, 2005). This study thus takes both students' linguistic and social backgrounds into consideration in the analysis. 
Parallel with these changes, socio-economic segregation and linguistic diversity between schools have increased (Skolverket, 2009). This shift towards more homogeneous groups can be hypothesized to lead to a covariation between the group composition and how the instruction is designed. Pedagogical equality in mathematics teaching could be defined as all students being given access to qualitatively comparable teaching in relation to their individual needs. If the group composition, with respect to students' social and linguistic background, affects the quality of teaching that students have access to, it could be defined as pedagogical segregation. The family background's influence over performance has been shown to increase in Sweden in recent years (Skolverket, 2009), which could be an effect of pedagogical segregation.

Using the multidimensional model for describing and analyzing mathematics instructional practice in multilingual classrooms, the main aim of this study is to investigate how different dimensions of responsibility for students' mathematics learning processes are related to their achievements. Another aim is to investigate the equality of mathematics teaching between varying group compositions.

\section{Mathematics instruction in multilingual classrooms}

The following section reviews research concerning what influences students' performance in mathematics. The main focus is on the instructional practice in multilingual classrooms.

In mathematics teaching, multilingualism can be addressed by considering two dimensions of home language, linguistic (native language) and social (everyday language) (Morgan, 2007). Similarly, the language of instruction can, in addition to a linguistic dimension, be characterized by everyday or formal mathematics language. Morgan (2007) argues that all mathematics classrooms are multilingual, and by using a form of pedagogy that switches between different dimensions of home language and language of instruction, students can access both mathematical ideas and powerful ways of thinking and speaking. Henceforth, in this paper, if nothing else is noted, home language and language of instruction will, however, allude to the linguistic dimension.

In line with this reasoning, there are studies supporting language resources as tools for mathematics learning (Barwell \& Clarkson, 2004; Howie, 2003; Morgan, 2005) and that it is important for the opportunities to learn mathematics that second language learners develop their language skills both in their first and their second language (Clarkson, 1992, 2007; Cummins, 2000; Jäppinen, 2005). To develop language skills, and to be able to use language tools, however, linguistically challenging teaching is needed (Cummins, 1984; Gibbons, 2002; Setati \& Adler, 2000). In this study, the linguistic dimension of students' language skills in the language of instruction is covered by the concept Competence in the Language of Instruction. There is a complex and mutual relation between the social and the linguistic dimension of a student's language skills, and it is important to pay attention to the influence from both on students' achievements (Hansson \& Gustafsson, 2011). The social dimension of home language is covered by the families' social and economic background (Bourdieu, 1984, p. 57). Sirin (2005) concluded that Socio-Economic Status (SES) at the student level is one of the strongest predictors of academic performance, and at the school level, the correlations are even stronger. The relationship between students' academic outcomes, and SES has been shown to be around 0.30 at the student level and 0.60-0.80 at the group level (Gustafsson, 1998; Hattie, 2009). In Sweden, the correlation between SES and achievement has increased in recent decades as schools have become more homogenous with respect to students' social and migrational background (Skolverket, 2009). The SES factor could also 
indirectly affect students' performances through its relation to underlying causes, e.g., possibilities to recruit qualified teachers and develop a homogeneous staff. The reasons for second language learners' weaker performances in mathematics, compared with their Swedish peers, are thus complex. Studies of effects of different language resources are, however, quite rare in previous research (Hattie, 2009). Cooper and Harries (2002, 2005), however, have studied the importance of students' prior experiences and found that second language learners' experiences often differ from students' in general. They argue that, if this is not taken into account in the teaching, students' socio-economic background could thus have a strong influence on learning. Relating mathematics to some version of the "real world", which alludes to previous experiences, could thus cause problems for children. "Real world tasks" require a lot of reading, and moreover, they also require awareness of the "everyday" knowledge of the world outside the classroom. Differences in mathematical understanding between different groups of students, in relation to social class, can thus be overestimated if realistic items are used when testing students (Cooper \& Dunne, 2000). Social class differences in the interpretation of realistic questions may underlie group differences in performance, rather than divergent mathematics skills (Cooper \& Dunne, 2005), which means that one must be cautious when interpreting test results.

The educational practice at the classroom level has been shown to have significance for explaining performance. Hattie (2009) synthesized research on effects of education in a compilation of more than 800 meta-analyses, with the main conclusion that fundamental principles of education, rather than methods of instruction, make some forms of education more effective than others. For second language learners, the need for scaffolding from a teacher to develop their mathematics skills is well documented. In prior research, how support could be given is also discussed. In a choice between focusing on mathematical vocabulary and engaging with students' mathematics, Moschkovich (1999) argues that it may be more productive to engage with their mathematics. Adler (2001), on the other hand, states that teachers have to balance between attention to mathematics and attention to language. This balancing concerns, among other things, not letting the teachers' intervention disempower the students from developing their thinking. In a model for how monolingual teachers could work with bilingual students in mathematics teaching, Moschkovich (2009) shows the importance of both teachers and students being active. Teachers are supposed to support a mathematical discussion using multiple interpretations, building on students' own views, and base the discussion on mathematical concepts. To facilitate learning in multilingual mathematics classrooms, Barwell (2008) highlights the importance of the discussion being based on students' own experiences. In this way, he argues, second language learners develop their own understanding of mathematics and the mathematical language they encounter. Clarkson (2005) emphasizes the importance of students achieving high competence in both their languages, and also the teacher's role in supporting this development. He concludes that it is important to encourage students to use both their first and second languages and also to engage expert colleagues and students' homes in their mathematics learning. Taken together, these studies show that teaching in multilingual classrooms is complex and that teachers have to balance different needs. The teacher should play an active role when teaching, but, at the same time, let the students themselves construct their knowledge. Teachers must teach in a way that stimulates students' language development, parallel with their mathematics development. They must also take into account each student's previous experiences.

Different dimensions of REL are embedded in structured mathematics learning, and in this study, it is further hypothesized that teachers' responsibility for students' mathematics learning causally influences their achievements. In the earlier study (Hansson, 2010), where 
a model of REL was developed, it turned out that responsibility for students' learning processes manifested itself in different ways in different types of teaching, such as in teacher- or student-centered teaching. Taking responsibility can thus not be regarded as a method or organization, but rather a dimension that permeates the various methods and forms of organization. Responsibility for students' learning processes in mathematics could thus be regarded as an example of a fundamental principle in mathematics education with the potential to affect students' opportunities to learn mathematics, rather than a method. In Sweden, where it cannot be taken for granted that the teacher takes considerable responsibility for students' learning processes, studying the relations between REL and students' mathematics performances is of particular interest.

In a longitudinal study, Baumert et al. (2010) used a multilevel structural mediation model to investigate effects of teachers' content knowledge (CK) and pedagogical content knowledge (PCK) on quality of instruction and student progress in mathematics. Baumert et al. showed that much of the variance in achievements was explained by the instructional quality, and they showed that higher levels of CK have no direct impact on either the potential for cognitive activation or on the individual learning support that teachers are able to provide. It is the level of PCK that is crucial in both these cases. However, teachers with higher CK scores were better able to align the material covered with the curriculum. There are similarities between the REL model (Hansson, 2010) and the mediation model by Baumert et al. (2010). Both aim to capture crucial dimensions of instructional quality with the power to predict students' achievements in mathematics. However, in the model by Hansson, cognitive activation and individual learning support are manifested in two different dimensions of REL. With this model, it could thus be possible to separate effects on students' mathematics performance between different dimensions of responsibility for the learning processes.

The conceptualization of the dimensions of instructional quality in the Baumert et al. study relates to findings in a meta-analysis by Seidel and Shavelson (2007), which established effects of domain-specific principles of education, rather than single teaching acts, and demonstrated the need for students to be supported and scaffolded in their learning activities, and not only being provided with challenging tasks. The importance of research design for the estimated effect sizes of instruction was also analyzed by Seidel and Shavelson (2007). Correlational survey studies showed lower teaching effects than experimental designs, which were interpreted as being due to proxy variables being used to capture teaching characteristics, rather than direct observation or video. It was also concluded that covariate adjustment models resulted in low to moderate estimates of teaching effects, because these models measure effects on status, not change in student outcomes. If, instead, individual growth curves for students or classes were estimated, which was rare in previous research, the effect sizes of teaching should be higher. Seidel and Shavelson (2007) concluded that the low effect sizes in correlational survey studies are due to the use of distal data, predominance of covariate adjustment models, and approaches taken when interpreting the natural variations in teaching.

An additional reason, not discussed in Seidel and Shavelson's (2007) paper, for the lower effects in standard survey research in the past decade, could also be that many studies are made on a disaggregated (student) level. However, this does not take all influencing factors into consideration (Gustafsson, 2003) because the standard research approaches tend to disregard the hierarchical, or multilevel, nature of educational data. When the data structure is such that students are nested within classes, this problem has typically been dealt with by aggregating the observations of the student-level units to the group-level units. However, such aggregation may change the meaning of variables and could introduce bias in the 
estimates of parameters. By instead taking full advantage of multilevel data through multilevel research approaches such as those adopted by Baumert et al. (2010), a more powerful approach for investigating effects of teaching is obtained.

When analyzing what affects students' learning gains in general, prior research has frequently focused on either individual underlying causes, such as motivation (Chiu \& Xihua, 2008), or general educational factors, such as family background and class size (Brüwiler \& Blatchford, 2011). When, instead, the instructional practice is investigated, effects of specific components of the learning process are often focused on, e.g. collaboration and feedback (Corbalan, Kester, \& van Merrienboer, 2009; Tolmie, et al., 2010). Clarkson's (2005) research on mathematics teaching concerns effects of second language students' language competences. The research previously reported in this section touches on the importance of specific fundamental principles of content activities in the teaching (Baumert, et al., 2010; Hattie, 2009; Seidel \& Shavelson, 2007). However, effects of different dimensions of REL have not been investigated, and this will be done in this study.

It is known that there is a connection between group composition and students' opportunities to learn mathematics. Such peer effects, which mainly concern the importance of the knowledge distribution in the teaching group, are demonstrated in several studies (Gustafsson, 2006; Hattie, 2009). Ethnically homogeneous groups have in Sweden been shown to have negative effects on school grades for all the students but primarily for students with a foreign background (Szulkin \& Jonsson, 2007). Several studies also show that the positive peer effects mostly appear for low-performing students when there are more high-performing peers in the group (see, e.g., Zimmer \& Toma, 2000). In previous research, a connection has also been established between the group composition and the kind of instruction being offered to students. Oakes (1998) showed the importance of teaching being adapted to different needs of different group compositions but also that group composition itself may have a negative impact on the teaching design. The latter is confirmed in other studies where groups or schools with a high SES level or high-performing students more often than others are offered instruction with more subjectoriented activities, challenging teaching or qualified teachers (Dumay \& Dupriez, 2007). Based on these results, it can be hypothesized that in Sweden, with increasing school segregation (Skolverket, 2009), pedagogical segregation occurs in mathematics education. Pedagogical segregation in this context means that not all students are given access to qualitatively comparable teaching in relation to their individual needs and that this lack of equal teaching is also related to the group composition. The relation between group composition, related to students' linguistic or social backgrounds, and the instructional practice will thus be investigated in this study.

The following research questions will be addressed:

- In what way are mathematics achievements in a multilingual classroom related to responsibility for students' learning processes?

- What are the relations between group composition with respect to students' linguistic or social backgrounds, and responsibility for students' learning processes? Is this group composition further related to students' achievements in mathematics?

\section{Method}

The empirical study was carried out in order to identify the relationships between teaching, mathematics performance, and group composition, taking students' socio-economic and linguistic background into account. This requires a method that allows for investigating 
the group level, which describes the classroom activities, at the same time as the influence on teaching derived from the student level can be taken into account. Accordingly, multilevel structural equation modelling (M-SEM) was used as the analytical instrument (Muthén, 1994), since this technique allows for specification of two-level models with latent variables, in which student- and group-level variables may be considered simultaneously. To develop the measurement models used in this study, confirmatory factor analysis (CFA) was employed (Brown, 2006). Manifest variables from both students' and teachers' perspectives have been used to indicate different dimensions of responsibility in mathematics instruction. To indicate the students' socio-economic background, manifest variables from the student perspective have been used. By means of a dummy variable, the students were clustered in two groups according to whether they were born abroad or in Sweden, and this was used to indicate students' language skills in the language of instruction. A standardized general measure of performance in mathematics was used as the outcome variable, as well as three variables representing the categorization of the results into the cognitive categories knowing, applying, and reasoning (Mullis, Martin, \& Foy, 2005). This section describes data sources and methods used, as well as the hypothesized models for the explanatory factors and the outcome variables. The measurement models for the construct REL and the background factor SES are mainly based on models developed in prior studies by Hansson (2010) and Hansson and Gustafsson (2011) and will only briefly be described in this paper. Readers are thus referred to those papers for more detailed documentation.

\subsection{Data sources}

The data source for the empirical study was the Trends in International Mathematics and Science Study, TIMSS 2003, (Mullis, Martin, Gonzalez, \& Chrostowski, 2004) conducted by the International Association for the Evaluation of Educational Achievement, focusing on mathematics for Swedish students in eighth grade. The Swedish sample comprised 4,256 students from 274 classes in 160 schools. In the data subset used, only classes with one mathematics teacher were included, and, furthermore, only those observations were included where both the student and the teacher had responded to the questionnaires (3,237 students in 217 classes). In addition to variables that describe students' performance in a mathematics test, observed variables describing different contextual factors are also included in the dataset. These variables are derived from both student and teacher questionnaires.

Several indices were used to assess model fit: chi-square test, root-mean-square error of approximation (RMSEA), the standardized root mean-square residual (SRMR), and also the comparative fit index (CFI). Values of less than 0.05 of the RMSEA index represent a "close fit", and models with values above 0.1 should be rejected (Brown, 2006). The SRMR was used as an absolute fit index, and values should be 0.08 or less (Brown, 2006). Because the chi-square statistic is very sensitive to sample size, chi-square/df ratio was also examined to check fit (Kline, 1998). For the goodness-of-fit index, CFI, a value of at least 0.95 is usually required to accept a model (Brown, 2006).

\subsection{Hypothesized models}

\subsubsection{Structural model}

To analyze the hypothesized relations between group composition and the different dimensions of REL, and between group composition and mathematics achievements, the two constructs Competence in the Language of Instruction and the cultural dimension of SES 
were included in the model, both on student and group levels. See Fig. 1 and Sections 3.2.2 and 3.2.3.

Competence in the Language of Instruction and the cultural dimension of SES also functioned as control variables when relations between REL and achievements were analyzed. To further analyze the hypothesized relations between REL and students' mathematics achievements, the multi-dimensional latent construct, represented by the three dimensions Teacher Activity, Student, and Mathematics Content was also included in both levels in the model; see also Section 3.2.4. Finally, to make it possible to analyze the hypothesized relation between REL and linguistic levels of the mathematics tasks, the dependent achievement variable, which is described in Section 3.2.5, was divided into four conceptually different variables: standardized Achievement and the three cognitive domains Knowing, Applying, and Reasoning. See Fig. 1.

\subsubsection{Language of instruction}

It was hypothesized that both achievements and instructional approaches are affected by students' linguistic abilities in the language of instruction (Cummins, 1984; Gibbons, 2002). TIMSS data do not offer variables that directly describe the students' language competences in the language of instruction. Instead, this has been indicated indirectly by the time students spent in Sweden and thus have had the opportunity to develop their language skills in the language of instruction (Collier \& Thomas, 2002). On the basis of information supplied in the student questionnaire, three groups of students with different migrational backgrounds were identified: students with a foreign background born outside Sweden $(N=267)$; students with a foreign background born in Sweden $(N=258)$; and students with a Swedish background $(N=2725)$. Here, foreign background meant that both parents were born in a country other than Sweden or that the student was born outside Sweden (Skolverket, 2004). A further grouping into the two categories born abroad and born in Sweden was shown to be most significant for the predictability of achievements on the group level, which was also in line with the hypothesized importance of length of residence in a country to develop skills in a
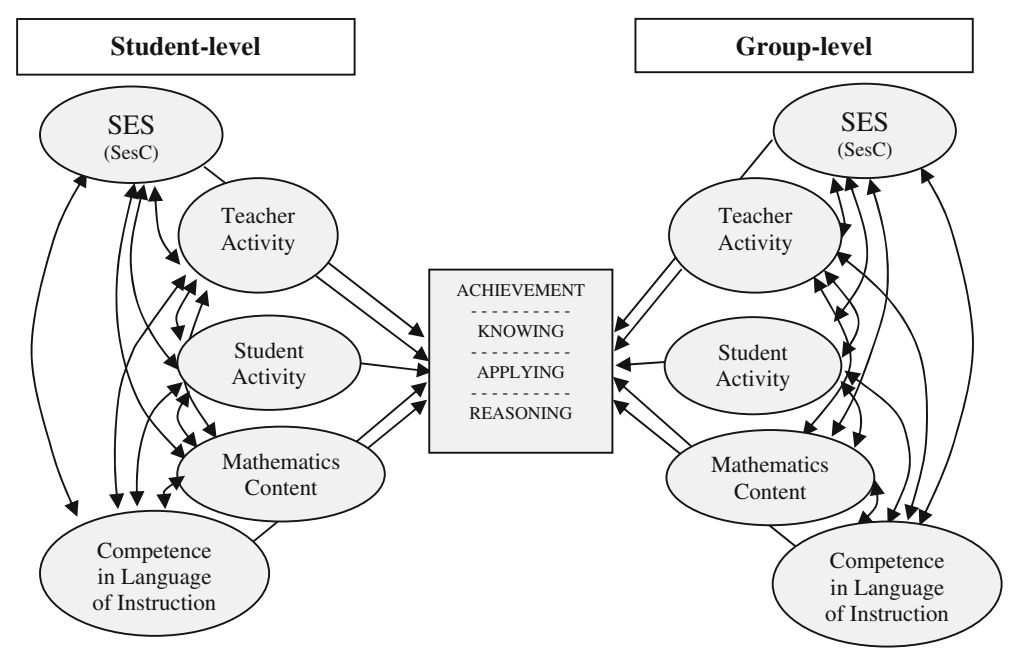

Fig. 1 Schematic representation of the hypothesized explanatory model REsponsibility for students' Learning processes (REL), student- and group-level 
second language (19.2\% of the variation in group-level achievement was explained by students' time in Sweden and $15.8 \%$ by students' foreign background). The grouping was done by assigning the dummy variable Competence in the Language of Instruction and aggregating to the group-level in the two-level SEM analyses. Thus, at the group level, the aggregated variable expresses the proportion of students within each group born abroad. Students defined as born abroad include those from Norway and Denmark, whose linguistic disadvantage when the instructional language is Swedish may be considered very small compared with those of other national origins. However, since only $5 \%$ of the students born abroad at the time the data were collected were of Nordic origin, the problem of inclusion of these students could be regarded as negligible. ${ }^{1}$

\subsubsection{Socio-economic status}

It was further hypothesized that the proportion of students with a high SES level in the group is related to achievements (Skolverket, 2009; Hattie, 2009; Sirin, 2005) and that this also is related to how mathematics teaching will be approached. According to a prior study (Hansson \& Gustafsson, 2011), a uni-dimensional measurement model for the cultural dimension of SES (SesC) was applied in the structural model.

The family cultural capital aspect of SES was hypothesized to characterize homes as being educationally oriented and supportive of student's academic achievements (Bourdieu, 1984; Coleman, 1988; Yang \& Gustafsson, 2004). A CFA model with one latent factor was thus hypothesized. This dimension was represented by the latent factor labelled SesC. The hypothesized model is shown in Fig. 2. The item BOOK, the number of books in the student's home, indicates the kind of family capital congruent with the symbolic and social expectations of the existing education system. The items MEDU, the mother's educational level, and FEDU, the father's educational level, are two other indicators of SesC. The item HFSG, the student's study aspirations, is another indicator that has a well-established relation to SES and cultural capital (Goldstein-Kyaga, 1995; Skolverket, 2004). See Fig. 2.

Hansson and Gustafsson (2011) concluded that this one-factor model for these indicators adequately represented the covariance structure for all groups of students, irrespective of their migrational background. However, when the measurement equivalence of $\mathrm{SesC}$ across migrational groups was investigated, metric, but not scalar invariance was observed. Metric

Fig. 2 The measurement model for socio-economic status, student-level

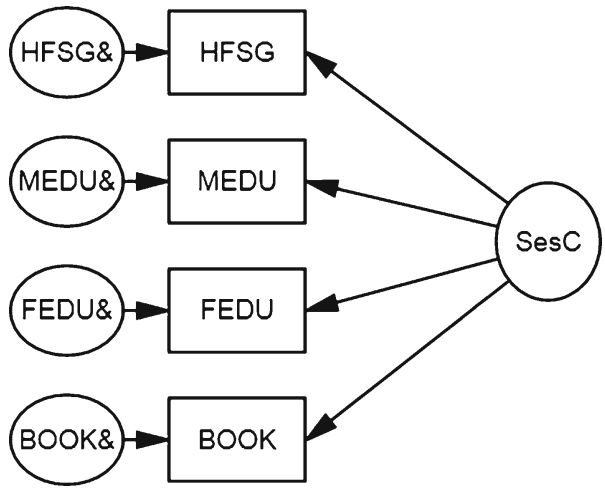

${ }^{1}$ Total Population Register in Sweden, 2003. Population statistics, SCB [Central Bureau of Statistics] 
invariance means that the latent variable as defined by the four indicators has the same meaning in all groups, and scalar invariance means that the levels of the indicator intercepts are equivalent across groups. Despite these indicators not having scalar invariance between groups of students, Hansson and Gustafsson (2011) recommended, for want of any better solution, using a model with parameters constrained to be equal across groups. Such a model is applied in this study.

\subsubsection{Responsibility for students' mathematics learning}

As presented in the "Section 1," it was hypothesized that responsibility for students' mathematics learning processes should have positive impact on student performance (Hansson, 2010). To investigate this hypothesis, a multi-dimensional measurement model for the latent construct responsibility for students' learning process was applied. Such a measurement model for REL was conceptualized and validated in a prior study by Hansson (2010). The model makes it possible to simultaneously focus on three dimensions of REL, hypothesized to have differential implications for mathematics performance. These dimensions are identified by combining information from both teachers and students about their perceptions of the teaching. See Fig. 3 .

The first factor, Teacher Activity, concerned to what extent teachers take responsibility for students' mathematics learning by actively and openly supporting students in their mathematics learning. This can be accomplished by, for example, highlighting and explaining the mathematics content, questioning and conversing with students, and organizing instruction so as to create conditions for interaction and social activities. Observed variables from both the student and the teacher questionnaires in the TIMSS data were selected to indicate this factor. From the student questionnaire, observed variables depicting lecturestyle presentations, tests, and problem solving were chosen, and from the teacher questionnaire, observed variables depicting lecture-style presentations, tests, and teachers asking students to work with a specific content and practicing computational skills were chosen. The second factor, Student Activity, concerned to what extent teachers take responsibility for handing over responsibility to the students for their own construction of knowledge by, for

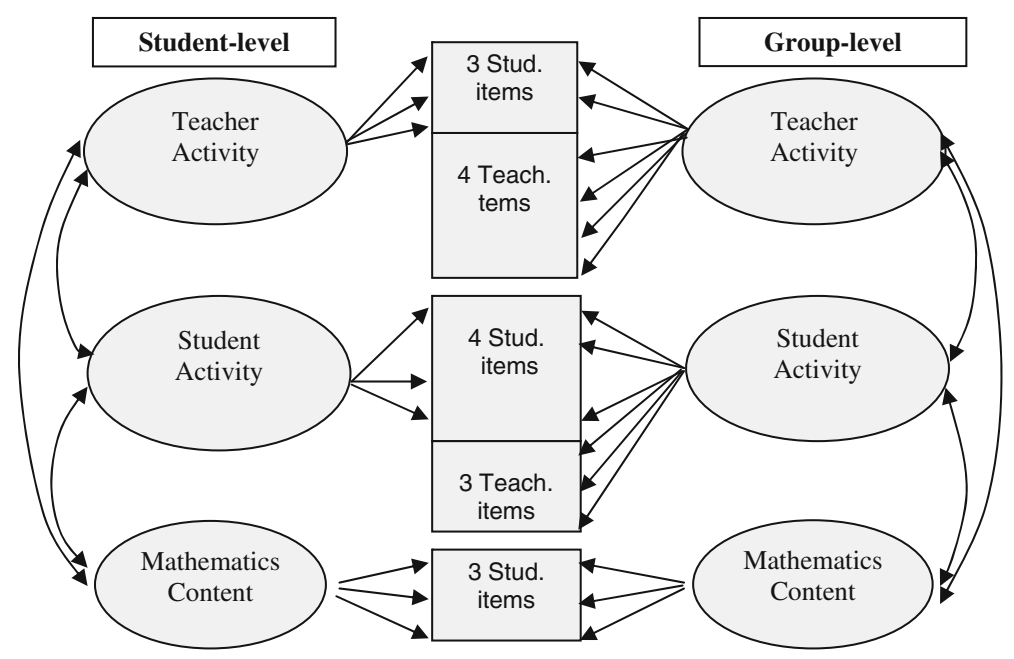

Fig. 3 The measurement model for REsponsibility for students' Learning processes (REL), student- and group-level. Notes. (Two-tailed Est./S.E. $<2.0$, P-value $>0.05$ ) 
example, encouraging them to reflect and reason about mathematical problems. Also for this factor, observed variables from both the student and the teacher questionnaires were selected. From the student questionnaire, variables depicting whether students are asked to relate what they learn to their daily life, if they review their homework, if they explain their answers to the class, and decide on their own which procedures to be used in solving complex problems were chosen. From the teacher questionnaire, observed variables relating to students' daily life, using homework as a basis for class discussion about the mathematics homework and asking students to explain their answers were chosen. Finally, the third factor, Mathematics Content, reflected the teacher's responsibility for highlighting the content relevant to the grade as the object of teaching. Three observed variables from the student questionnaire were used as indicators: practice adding, subtracting, multiplying, and dividing without using a calculator; working with fractions and decimals; and writing equations and functions to represent relationships. See Fig. 3. The potential of the model to account for observed relations in empirical data was evaluated by using Swedish data from TIMSS 2003, eighth grade. The intra-class correlation suggested sizeable class effects on observed variables (ICCs 0.051-0.291), and the model showed a reasonably good fit $(\mathrm{CFI}=0.863$ and RMSEA $=0.036)$. The model-fit at class level was a bit harder to interpret than the fit at student level (SRMR was 0.027 at student-level and 0.126 at class level). However, the impression of poor model fit given by the SRMR index was assumed to be due to limitations of this index when applied in multilevel structural equation models (Brown, 2006). The substantial meaningfulness and the interpretability of the model also contributed to the evaluation of the fit. The latent variables were all positively correlated, but no correlation was higher than 0.8 , which supported the hypothesis that the latent factors represented different constructs (Brown 2006), and all factor loadings in the model were statistically significant. They also corresponded substantially to the underlying theoretical starting points for the model. For more detailed descriptions of the model, see Hansson (2010).

\subsubsection{Mathematics achievement}

In addition to a standardized total mathematics score, Achievement, three outcome variables depicting cognitive domains were also used in the M-SEM models: Applying knowledge and conceptual understanding, Knowing facts/procedures/concepts, and Reasoning.

To investigate whether it is more important for students with weakly developed skills in the language of instruction than for others that the teacher takes responsibility for mathematics instruction, it was hypothesized that the size of the correlation between REL and achievements is related to linguistic dimensions of the mathematics tasks (Barwell \& Clarkson, 2004; Morgan, 2005; Setati \& Adler, 2000). This means that to enable students to perform in mathematics, it is more important for students with weakly developed language skills in the language of instruction than for others that the teacher takes responsibility for mathematics instruction. The mathematics framework for TIMSS 2003 is, in addition to content domains, organized according to cognitive domains. In this study, the cognitive domains are assumed not only to be related to different cognitive aspects but also to linguistic dimensions.

The cognitive achievement variable Knowing covers what basic skills students need to know (Mullis et al., 2005), and words are not frequent in tasks testing such knowledge. Some tasks are in words, which place the problem situation in a context, but most are not [example: What is the value of $1-5 \cdot(-2)$ ? (M032612)].

The cognitive achievement variable Applying focuses on the ability of students to apply what they know to solve routine problems or answer questions (Mullis et al., 2005). This variable, however, encompasses a larger number of words when testing how students use 
essential mathematics, which forms a foundation for mathematical thought, in solving routine problems [example: A garden has 14 rows. Each row has 20 plants. The gardener then plants 6 more rows with 20 plants in each row. How many plants are now there altogether? (M032671)].

The third cognitive achievement variable Reasoning goes beyond the solution of routine problems to encompass unfamiliar situations, complex contexts, and multi-step problems (Mullis et al., 2005). To arrive at solutions to non-routine problems, which go beyond being purely mathematical, but also have real-life settings, both understanding and using words are essential [example: A computer club had 40 members, and $60 \%$ of the members were girls. Later, 10 boys joined the club. What percent of the members are now girls? Show the calculations that lead to your answer (M032233)].

In this study, both Applying and Reasoning are hypothesized to be related to linguistic dimensions of the mathematics tasks, and the Reasoning domain is hypothesized to be the most linguistically influenced.

\subsubsection{The analytical procedure}

The analytical focus in this study concerns variation at group level, which is indicated by both teacher and aggregated student data. It is variation at the classroom level that is expected to be related to differences in instructional approaches. Variations at the student-level, however, need not be related to dimensions of instruction in observational data, because of, among other things, reverse causality, which, for example, may be caused by the teaching being adapted to the students' level of achievement (Gustafsson, 2010). However, the mechanisms, which cause reverse causality at the individual level, need not be present at other levels of observation. For example, students may vary in the amount of time spent on homework, poorly achieving students having to spend more time than their high-achieving classmates. At the student level, this causes a negative relation between time invested in homework and achievement. Teachers also may vary in their eagerness to give homework to students as an expression of an instructional strategy, which is more or less independent of the group composition. Thus, at the group level, there may be a positive causal effect of homework on achievement (Gustafsson, 2010 , p. 7). Aggregating data is thus an approach to prevent threats to causal inference. Furthermore, Gustafsson (2010) argues that estimates of class means are more reliable than student responses to single questionnaire items.

The analytical approach in this study was to investigate the influence of one dimension of the construct REL at a time. Analyses with three- and two-factor models either produced no estimates at all, or produced estimates difficult to interpret. These problems were likely due to the high intercorrelations between the factors; see Table 1 (Hansson, 2010).

Table 1 Factor correlation, student- and group-level

\begin{tabular}{|c|c|c|c|c|c|c|}
\hline & \multicolumn{2}{|c|}{$\begin{array}{l}\text { REL factor } 1 \text {, teacher } \\
\text { activity }\end{array}$} & \multicolumn{2}{|c|}{$\begin{array}{l}\text { REL factor 2, student } \\
\text { activity }\end{array}$} & \multicolumn{2}{|c|}{$\begin{array}{l}\text { REL factor } 3 \text {, } \\
\text { mathematics content }\end{array}$} \\
\hline & Student-level & Group-level & Student-level & Group-level & Student-level & Group-level \\
\hline $\begin{array}{l}\text { REL factor } 1 \text {, teacher } \\
\text { activity }\end{array}$ & 1.000 & 1.000 & & & & \\
\hline $\begin{array}{l}\text { REL factor } 2 \text {, student } \\
\text { activity }\end{array}$ & 0.781 & 0.772 & 1.000 & 1.000 & & \\
\hline $\begin{array}{l}\text { REL factor 3, mathematics } \\
\text { content }\end{array}$ & 0.702 & 0.551 & 0.511 & 0.580 & 1.000 & 1.000 \\
\hline
\end{tabular}


Finally, the background variables SesC and Competence in the Language of Instruction were one by one included in the model. To control the estimated correlation between REL and achievements for influences from the background factors, $\mathrm{SesC}$ and Competence in the Language of Instruction functioned as control variables. The aim was to investigate the relation between these factors and achievements, and also to investigate their influence on how the instructional practice was performed. To discern the unique influence from each background factor, the other was used as control variable.

For the analyses reported here, the Mplus (Muthén \& Muthén, 1998-2004) program was used in the STREAMS modelling environment (Gustafsson \& Stahl, 2005). The effect size, comparable with Cohen's $d$, has been calculated by using the following formula (Tymms, 2004): DELTA $=2 \cdot B \cdot$ SDpredictor/Se, where $B$ is the unstandardized regression coefficient in the multilevel model, SDpredictor is the standard deviation of the predictor variable at the class level, and Se is the residual standard deviation at the student level.

\section{Results}

This section begins with a descriptive overview of the relations among the background factors and their relations with achievements. Then, the relations between the three dimensions of REL and achievements are investigated one at a time.

The models in the analysis showed reasonably good fit (CFI values between 0.749 and 0.902, RMSEA between 0.041 and 0.050). Compared with the student level, SRMR values, which were between 0.030 and 0.037 , the fit at the group level was a bit harder to interpret with values higher than the suggested criterion (SRMR between 0.131 and 0.198). As the modification indices on the group level showed no indications of local misfit, the impressions of poor model fit signalled by the SRMR index may be due to limitations of this index when applied in multilevel structural equation models (Brown, 2006). The substantial meaningfulness of the model and the possibilities of interpretation also contribute to the evaluation of the fit.

\subsection{The background factors}

Both SesC and Competence in the Language of Instruction were related on the group level to achievements. The correlation between group composition in terms of SesC and achievements, when controlled for Competence in the Language of Instruction in the group, was substantial and amounted to around 0.7 in all factor models (Teacher Activity, Student Activity, and Mathematics Content). The correlation between group composition in terms of Competence in the Language of Instruction and achievements, however, was only weakly significant in one of the models. This shows that particularly SesC explains a significant part of the variation in performance between classes. This means that groups with a high proportion of students with low SesC have lower average scores on the mathematics tests than other classes. The same explicit result is, however, not found for groups with a high proportion of students with expected weak skills in the language of instruction.

Significant correlations between group composition in terms of Competence in the Language of Instruction and SesC, respectively, and the three factors representing different dimensions of REL were also obtained. The background factor Competence in the Language of Instruction showed significant relations to both the REL factors Teacher Activity and Student Activity, but not to the factor Mathematics Content. After control for SesC, 
correlations were around -0.6 with the REL factor Teacher Activity and around -0.4 with the factor Student Activity. Also, group composition in terms of SesC showed, after control for Language Competence, significant relations to the REL factor Teacher Activity with correlations of around 0.5. SesC was also related to the REL factor Student Activity, but only for the outcome variable Applying (correlation, 0.3). Group composition in terms of SesC was, similar to Competence in the Language of Instruction, not correlated to the factor Mathematics Content. The proportion of students with a specific SesC level in the class, or the proportion of students with a specific level of competence in the language of instruction, was related to how REL has come to be framed in the classroom. This indicates the presence of a selection effect on which instruction is offered, which could also be expressed as pedagogical segregation in cases where student's individual need for support are not met because of composition of the group. Thus, classes with a high proportion of students with expected low language proficiency in the language of instruction or with low socioeconomic status more seldom than other classes receive instruction characterized by the teacher taking a large part of the responsibility for students' mathematics learning.

The varying, yet substantial, relations between, on the one hand, the background variables Competence in the Language of Instruction and SesC, and on the other, achievements and teaching responsibilities factors, motivated control for influence of these background variables on the estimated correlations with achievements in the structural model. However, the relation between Competence in the Language of Instruction and SesC (a correlation of about -0.55$)$ stresses the need for cautious interpretation.

\subsection{The responsibility for students' mathematics learning}

\subsubsection{The relationship between the REL factor teacher activity and mathematics performance}

The REL factor Teacher Activity showed significant positive relations with all the four achievement variables. The highest correlations between Teacher Activity and achievements were obtained for linguistically influenced outcome variables, which supports the hypothesis that the importance of REL could be related to students' skills in the language of instruction. However, after control for the group composition in terms of Competence in the Language of Instruction, the highest correlation between the REL factor Teacher Activity and achievements was observed for the second most linguistically influenced outcome variable, Applying (see Table 2).

The REL dimension Teacher Activity, representing teachers taking responsibility for students' learning processes by organizing and offering a learning environment where the teacher actively and openly supports the students in their mathematics learning, was positively related to the classes' achievement levels. However, some of this correlation was related to the proportion of students in the class with a specific level of competence in the language of instruction and some to the proportion of students with a specific SesC level. After these background factors were taken into account, about $9 \%$ of the variation in achievements between classes was still related to the level of responsibility for students' learning process, REL, in terms of the dimension Teacher Activity. This corresponds to an effect size of 0.44 when the variance components have been transformed into an effect size comparable with Cohen's $d$ (Tymms, 2004). Furthermore, this dimension of responsibility for students' learning process had the highest importance for mathematics tasks concerning applications of knowledge and reasoning, and the least importance for tasks concerning basic mathematics. 
Table 2 Standardized beta-coefficients between outcomes and the REL factor teacher activity, differentiated for the four outcome variables (group-level)

\begin{tabular}{|c|c|c|c|c|c|c|c|c|}
\hline \multirow[t]{2}{*}{ Model } & \multicolumn{2}{|c|}{ Achievement } & \multicolumn{2}{|c|}{ Knowing } & \multicolumn{2}{|c|}{ Applying } & \multicolumn{2}{|c|}{ Reasoning } \\
\hline & $\beta$ & $t$-value & $\beta$ & $t$-value & $\beta$ & $t$-value & $\beta$ & $t$-value \\
\hline Not controlled & 0.61 & 6.65 & 0.58 & 5.13 & 0.65 & 5.97 & 0.67 & 6.07 \\
\hline $\begin{array}{l}\text { Controlled for competence in } \\
\text { the language of instruction }\end{array}$ & 0.44 & 3.30 & 0.48 & 3.69 & 0.57 & 3.43 & 0.54 & 3.11 \\
\hline Controlled for SesC & 0.26 & 2.91 & 0.27 & 2.84 & 0.31 & 3.15 & 0.32 & 2.91 \\
\hline $\begin{array}{l}\text { Controlled for competence in the } \\
\text { language of instruction and SesC }\end{array}$ & 0.29 & 2.50 & 0.30 & 2.75 & 0.35 & 2.71 & 0.33 & 2.36 \\
\hline
\end{tabular}

\subsubsection{The relationship between the REL factor student activity and mathematics performance}

The REL factor Student Activity also showed significant and positive relations to all achievement variables. However, unlike the factor Teacher Activity, no significant relations remained after control for the group composition in terms of Competence in the Language of Instruction and SesC. The highest correlations with achievements were for the factor Student Activity, similar to that of Teacher Activity, obtained for linguistically influenced variables. Similar to the models with the factor Teacher Activity, the highest correlation was estimated with the outcome variable Applying and the lowest correlation with the outcome variable Knowing, which concerns basic mathematics (see Table 3).

The mathematics teaching characterized by teachers taking responsibility for initiating students to take responsibility for constructing their own mathematics knowledge appeared, at first glance, to influence achievement. However, this correlation disappeared altogether when controlling for group composition in terms of Competence in the Language of Instruction and SesC. Students' responsibility for constructing their own mathematics knowledge is thus not related to achievement.

Table 3 Standardized beta-coefficients between outcomes and the REL factor student activity, differentiated for the four outcome variables (group-level)

\begin{tabular}{|c|c|c|c|c|c|c|c|c|}
\hline \multirow[t]{2}{*}{ Model } & \multicolumn{2}{|c|}{ Achievement } & \multicolumn{2}{|c|}{ Knowing } & \multicolumn{2}{|c|}{ Applying } & \multicolumn{2}{|c|}{ Reasoning } \\
\hline & $\beta$ & $t$-value & $\beta$ & $t$-value & $\beta$ & $t$-value & $\beta$ & $t$-value \\
\hline Not controlled & 0.28 & 2.55 & 0.30 & 2.79 & 0.33 & 3.06 & 0.32 & 2.81 \\
\hline $\begin{array}{l}\text { Controlled for competence in the } \\
\text { language of instruction }\end{array}$ & $0.11 \mathrm{~ns}$ & 0.88 & a & & $0.16 \mathrm{~ns}$ & 1.30 & $0.12 \mathrm{~ns}$ & 0.94 \\
\hline Controlled for SesC & $0.09 \mathrm{~ns}$ & 1.21 & $0.11 \mathrm{~ns}$ & 1.55 & $0.13 \mathrm{~ns}$ & 1.88 & $0.13 \mathrm{~ns}$ & 1.69 \\
\hline $\begin{array}{l}\text { Controlled for competence in the } \\
\text { language of instruction and SesC }\end{array}$ & $0.09 \mathrm{~ns}$ & 1.06 & $0.11 \mathrm{~ns}$ & 1.24 & $0.14 \mathrm{~ns}$ & 1.55 & $0.11 \mathrm{~ns}$ & 1.21 \\
\hline
\end{tabular}

ns non-significant

${ }^{\mathrm{a}}$ No estimated parameters 
Table 4 Standardized beta-coefficients between outcomes and the REL factor mathematics content, differentiated for the four outcome variables (group-level)

\begin{tabular}{|c|c|c|c|c|c|c|c|c|}
\hline \multirow[t]{2}{*}{ Model } & \multicolumn{2}{|c|}{ Achievement } & \multicolumn{2}{|l|}{ Knowing } & \multicolumn{2}{|l|}{ Applying } & \multicolumn{2}{|c|}{ Reasoning } \\
\hline & $\beta$ & $t$-value & $\beta$ & $t$-value & $\beta$ & $t$-value & $\beta$ & $t$-value \\
\hline Not controlled & $-0.26 \mathrm{~ns}$ & -1.7 & $-0.22 \mathrm{~ns}$ & -1.45 & $-0.18 \mathrm{~ns}$ & -1.22 & $-0.14 \mathrm{~ns}$ & -0.96 \\
\hline $\begin{array}{l}\text { Controlled for competence in } \\
\text { the language of instruction }\end{array}$ & -0.36 & -2.50 & -0.32 & -2.24 & -0.28 & -2.04 & $-0.23 \mathrm{~ns}$ & -1.79 \\
\hline Controlled for $\mathrm{SesC}$ & $-0.12 \mathrm{~ns}$ & -1.43 & $-0.09 \mathrm{~ns}$ & -1.18 & $-0.05 \mathrm{~ns}$ & -0.68 & $-0.01 \mathrm{~ns}$ & -0.14 \\
\hline $\begin{array}{l}\text { Controlled for competence in } \\
\text { the language of instruction } \\
\text { and SesC }\end{array}$ & $-0.15 \mathrm{~ns}$ & -1.60 & $-0.13 \mathrm{~ns}$ & -1.40 & $-0.08 \mathrm{~ns}$ & -0.97 & $-0.05 \mathrm{~ns}$ & -0.53 \\
\hline
\end{tabular}

\subsubsection{The relationship between the REL factor mathematics content and mathematics performance}

The dimension of REL reflecting teachers' responsibility for highlighting the mathematical content as objects of teaching was related to achievement in quite a different way than the two previous reported dimensions. Without controlling for group composition in terms of Competence in the Language of Instruction or SesC, no relations between the REL factor Mathematics Content and achievements were shown. However, when it was controlled for Competence in the Language of Instruction, the factor turned out to be significantly negatively related to most of the achievement variables (not on Reasoning), with the highest correlation with the standardized variable, Achievement. See Table 4. The weakest correlation was shown with the outcome variable Applying.

Taking responsibility for putting emphasis on mathematics content and not just the teaching activities seems, after control for group composition in terms of Competence in the Language of Instruction, to be related to low achievement levels. However, this relation disappeared when it was also controlled for $\mathrm{SesC}$, which indicates that this dimension could be related to the SES level of the group and not just to the intended instruction.

\section{Discussion}

This study investigated how students' mathematics achievements are affected by how the responsibility for their learning processes is reflected in the teaching. Moreover, it investigated the equality of mathematics teaching between varying classroom compositions with respect to students' social and linguistic background. The results indicate that, when much of the responsibility for students' learning is passed over to the students themselves, it is negatively related to the groups' performance. However, if the teacher takes responsibility by organizing and offering a learning environment where the teacher actively and openly supports the students in their mathematics learning, and where the students are also active and learn mathematics themselves, the groups produce higher results. The empirical findings further demonstrate that group composition is related to both achievement level and teaching design. Classes with a large proportion of students with a low socio-economic status or with expected weak competences in the language of instruction have lower mathematics results, and mathematics teaching for these classes is less often characterized by teachers taking a 
major responsibility for students' learning processes by organizing and offering a supportive learning environment than it is for other classes.

Vygotskij's and Brousseau's perspectives on teachers' engagement and students' construction of knowledge (Brousseau, 1997; Vygotskij, 1978, 1986) have formed a part of the theoretical basis of the instructional model developed in a previous study (Hansson, 2010), identifying and describing different dimensions concerning teachers' responsibility for both teaching and guiding and for letting students themselves construct their own knowledge. On the basis of these theoretical starting points, the first research question investigated the hypothesis that there is a positive influence on students' mathematics performance when teachers take responsibility for different dimensions of mathematics teaching. Because students were not randomly assigned to classes with different approaches to responsibility for learning, it was necessary to control for the influence of individual background factors if these relationships are to be interpreted in causal terms (Gustafsson, 2010). After controlling for the proportion of students in the group with expected weak competences in the language of instruction and for the level of SesC, the REL factor Teacher Activity explained about 9\% of the achievement variance at the class level, which corresponds to an effect size of 0.44 . This result supports the assumed positive relationship between students' performances and teaching characterized by teachers taking responsibility for students' learning processes by organizing and offering a learning environment where they actively and openly support the students in their mathematics learning. There is thus reason to tentatively assume that the observed correlation indicates a causal relationship. The result is in line with Vygotskij's theory about the importance of teachers taking responsibility for supporting, or scaffolding (Bruner, 1960) the student's development in the zone of proximal development. It is also in line with the importance that Brousseau ascribes the institutionalization of the knowledge, i.e., the teacher's tool for supporting pupils' knowledge progress. With the external perspective on the knowledge generated through the institutionalization, students' individual knowledge will be socially and culturally accepted and thus useful outside the school context. The result is also in line with prior empirical results that scaffolding in general is important for students' mathematics learning (Brousseau, 1997; Bruner, 1960; Cummins, 1984; Gibbons, 2002; Vygotskij, 1926/1997, 1986) and, in particular, for second language learners (Clarkson, 1992, 2007; Cummins, 2000; Jäppinen, 2005). These students need support to develop their mathematics skills and also their language skills. Their previous experiences must also be considered. The importance of such teacher intervention in mathematics teaching is highlighted in prior studies (Adler, 2001; Barwell, 2008; Clarkson, 2005; Moschkovich, 1999, 2009). Although these researchers differ in their view of certain aspects of teaching, they show a consensus as regards the teacher's critical importance to students' opportunities to learn mathematics.

The three dimensions of REL were hypothesized to have differential implications for students' mathematics performance. According to the results of this study, the factors also behaved in line with this hypothesis, although some uncertainties emerged concerning the validity of the factors. Thus, the REL factor Student Activity, students' constructing their own mathematics knowledge, was indeed positively correlated with students' performances in mathematics, but, when controlling for group composition related to the factors Competence in the Language of Instruction and $\mathrm{SesC}$, this correlation vanished. It is therefore difficult to determine whether the correlation can be attributed to student activities on their own or to these students generally having better learning conditions. The result is, however, in line with the theoretical assumption that students construct their own knowledge and Vygotskij's theory of the importance of communication, language and interaction in the learning process. It is also consistent with Brousseau's theory, which has formulated the 
importance of students' mathematical learning being stimulated by a-didactical situations, adapted to students' prior knowledge. The fact that the effects of students' own work seems to be so closely linked to their linguistic skills and socio-economic background could possibly be explained by results in previous research, showing the importance of the type of mathematics tasks that students work with (Cooper \& Dunne, 2000, 2005). Textbooks or other written documents are often used for students' own work. This presupposes, however, that students with weak language skills get language support and that "real-world tasks" are based on students' own well-known experiences (Cooper \& Harries, 2002, 2005). If this is not the case, the effects of students' own work could be expected to be in line with the results of this study, that is to say that social class explains much of the teaching effects. The fact that social class differences may underlie group differences in performance, rather than divergent mathematics skills, is shown by Cooper and Dunne (2005). To determine the effects of students' own work in mathematics, it is therefore essential to study in more detail the nature of that work. This could be a natural continuation based on the results of this study. However, the fact that students take responsibility for their own learning does not mean that the teacher's responsibility decreases, because, according to both Brousseau and Vygotskij, the teacher maintains his/her role to support students in their individual learning process and to make their knowledge general and not individual. These mechanisms are referred to in Brousseau's theory as institutionalization.

The second research question concerned relations between classroom composition, related to students' linguistic or social backgrounds, and the way teachers are taking responsibility for different dimensions of the mathematics teaching. The increasing proportion of students with migrational background in the Swedish mathematics classrooms made it interesting to investigate whether groups with a high proportion of students with expected weak competence in the language of instruction more often than others encounter teaching where teachers take responsibility for offering a learning environment supportive of their language and mathematics development. The hypothesis that REL would be more significant for second language learners' mathematics performance has not been explicitly examined in this study, but the results showing that the relationship between the REL and students' outcomes is stronger for tasks having a contextual and linguistic dimension, strengthen the hypothesis. This is also in line with findings in Cooper and Dunne's (2000, 2005) and Cooper and Harries' $(2002,2005)$ prior research, which is discussed above. However, the study showed that classes with a high proportion of students with expected weak competences in the language of instruction or with a low level of SesC, more seldom than others encounter teaching where the teacher takes responsibility for students' mathematics learning. If this is related to the increasing proportion of students with foreign background in classes, and the increase in students' independent work in Sweden, this may mean that a large proportion of students in compulsory school do not receive the teaching they need to succeed in their mathematics studies. Mathematics teaching could thus be viewed as not equivalent for all teaching groups, which means that it is characterized by pedagogical segregation.

If the variations in performance could be explained by pedagogical segregation, the inferior results could be viewed as segregation effects mediated through mathematics teaching. The causes of pedagogical segregation are of course complex. For example, because of lack of skills, time, or resources, teachers may have had difficulties facing problems arising as a consequence of the increasing school segregation with increasingly homogeneous teaching groups. Teachers' expectations and preference to challenge skilled students, or their avoidance of whole-class teaching, with interaction and mathematics talk, in groups with many students with weak competences in the language of instruction, may 
also have contributed to unequal teaching. Students in homogeneous groups could be less able to manage their studies, because of the peer effect (Gustafsson, 2006; Hattie, 2009; Szulkin \& Jonsson, 2007; Zimmer \& Toma, 2000). If the students in these groups also are offered instruction not supportive of their learning, it will create a doubly negative effect for students. Since school cannot create social change, pedagogical segregation results in school refraining from the only opportunity available to support students' learning. It is thus essential to further investigate what mechanisms are behind the pedagogical segregation.

To conclude, this study shows that, if the teacher takes responsibility for students' learning processes in mathematics instead of this responsibility being handed over to the students themselves, this has a positive influence on students' mathematics performance. The results also show that students with poor skills in the language of instruction more seldom than others receive such instruction. Also, groups with a majority of students from homes with low socio-economic status are affected by this pedagogical segregation. A main implication of the findings in this study is that the widespread and heavy use in Sweden of individualized ways of working in mathematics with much of the responsibility for the learning process handed over to the students themselves could be questioned. This teaching culture, which has emerged in mathematics education, is against the basic idea of both Vygotskij's and Brousseau's theories about the teacher's responsibility for supporting students' learning progress. Student's mathematics knowledge will not become institutionalized, which means that that students' learning processes could be hindered, and their knowledge may remain individual and thus not suitable for use in respect to contexts outside the school. It is also important to note that previous studies have shown that second language learners of mathematics are not always going to be underperforming. If their proficiency in the language of instruction and in their home languages improves, they can potentially go on to achieve more highly than the average (Clarkson, 1992). This presupposes, however, that the teacher takes responsibility for enabling these students to develop their language skills even when they learn mathematics. The findings could contribute to explaining the general decline in mathematics performances in Sweden in recent decades and also the increasing gap between different groups of students. The hypothesized effects of pedagogical segregation should thus be further researched in order to determine this contribution.

Even though the M-SEM approach offers a powerful method of guarding against threats to valid causal inference by invoking control for selection effects, it may not be able to control for all threats. While the factor of SesC accounted for at least $50 \%$ of the class-level variance in achievement, there may be mechanisms of selection and reverse causality related to the level of achievement of the class. Teachers could, for example, have higher expectations as regards well-performing students, and students with Swedish background, than others, and thus stimulate them to make progress in mathematics by teaching in accordance with the REL factor Teacher Activity. Perhaps teachers also find it difficult to carry out coherent teaching in groups with many low performers or linguistically weak students. If more background information was available, and in particular the initial level of student achievement, such threats to causal inference could be better prevented. The cross-sectional data from the international studies do not offer initial measures of achievement, but, by adding a follow-up component in a longitudinal design, such information can be collected (see, e.g., Baumert et al., 2010). With such a design, it would also be possible to acquire more information about teacher background and different aspects of the teaching, which would allow for investigations of the mediating mechanisms through which REL affects outcomes. It would, therefore, be of great interest to use such a longitudinal approach in future research. 
Some further limitations of the study should also be acknowledged. A fairly blunt measure of the control variable "students' competences in the language of instruction" was used. This measure indicates whether students are born abroad or in Sweden, but it does not take into account group variation or linguistic weaknesses in other student groups. Access to more precise background information concerning, for example, students' reading literacy would have improved the validity of the study. What must also be taken into consideration is that the second language learners performed the mathematics test in their second language, and thus, the validity of the test results must be taken into account. In previous research, it has been established that the interaction of student, item, and language could be a main source of score variation for second language learners when tested in a mathematics test (Solano-Flores \& Li, 2009). The fact that the interpreted meaning of the test items used could vary with social class (Cooper \& Dunne, 2005) could result in the performance level of low-SES students being underestimated, compared with their actual competence level. Furthermore, the M-SEM approach currently only allows for simultaneously analyzing two levels, but, in the data, three levels can be identified: student, class, and school levels. It could be that relations on the class level are influenced by organizational conditions on the school level. Such school effects thus remain to be investigated in future studies.

Open Access This article is distributed under the terms of the Creative Commons Attribution License which permits any use, distribution, and reproduction in any medium, provided the original author(s) and the source are credited.

\section{References}

Adler, J. (2001). Teaching mathematics in multilingual classrooms. Dordrecht: Kluwer Academic.

Barwell, R. (2008). Empowerment, EAL and the national numeracy strategy. International Journal of Bilingual Education and Bilingualism, 8(4), 313-327.

Barwell, R., \& Clarkson, P. C. (2004). Researching mathematics education in multilingual contexts:Theory, methodology and the teaching of mathematics. Paper presented at the 28th Conference of the International Group for the Psychology of Mathematics Education. Bergen: PME.

Baumert, J., Kunter, M., Blum, W., Brunner, M., Voss, T., Jordan, A., et al. (2010). Teachers' mathematical knowledge, cognitive activation in the classroom, and student progress. American Educational Research Journal, 47(1), 133-180.

Bernstein, B. (2000). Pedagogy, symbolic control and identity: Theory, research and critique. Lanham: Rowman and Littlefield.

Bourdieu, P. (1984). Distinction. Cambridge: Harvard University Press.

Brousseau, G. (1997). In N. Balacheff, M. Cooper, R. Sutherland, \& V. Warfield (Eds.), Theory of didactical situations in mathematics 1970-1990/by Brousseau. Dordrecht: Kluwer Academic Publishers.

Brown, T. A. (2006). Confirmatory factor analysis for applied research. New York: The Guilford Press.

Bruner, J. (1960). The process of education. Cambridge: Harvard University Press, cop.

Brüwiler, C., \& Blatchford, P. (2011). Effects of class size and adaptive teaching competency on classroom processes and academic outcome. Learning and Instruction, 21(1), 95-108.

Carlgren, I., Klette, K., Myrdal, S., Schnack, K., \& Simola, H. (2006). Changes in Nordic teaching practices: From individualised teaching to the teaching of individuals. Scandinavian Journal of Educational Research, 50(3), 301-326.

Chiu, M. M., \& Xihua, Z. (2008). Family and motivation effects on mathematics achievement: Analyses of students in 41 countries. Learning and Instruction, 18(4), 321-336.

Clarkson, P. C. (1992). Language and mathematics: A comparison of bilingual and monolingual students of mathematics. Educational Studies in Mathematics, 23(4), 417-429. 
Clarkson, P. C. (2005). Two perspectives of bilingual students learning mathematics in Australia: A discussion. In D. Hewitt \& A. Noyes (Eds.), British congress of mathematics education conference proceedings (pp. 33-40). Warwick: British Society for Research into Learning Mathematics.

Clarkson, P. C. (2007). Australian Vietnamese students learning mathematics: High ability bilinguals and their use of their languages. Educational Studies in Mathematics, 64(2), 191-215.

Coleman, J. S. (1988). Social capital in the creation of human capital. In C. Calhoun, J. Gerteis, J. Moody, S. Pfaff, \& I. Virk (Eds.), Contemporary sociology theory (pp. 110-116). Malden: Blackwell Publishing.

Coleman, D. (2006). Immigration and ethnic change in low-fertility countries: A third demographic transition. Population and Development Review, 32(3), 401-446.

Collier, V. P., \& Thomas, W. P. (2002). A national study of school effectiveness for language minority students, long-term academic achievement. Santa Cruz: University of California, Centre for Research on Education, Diversity \& Excellence.

Cooper, B., \& Dunne, M. (2000). Assessing children's mathematical knowledge. Social class, SES and problem-solving. Philadelphia: Open University Press.

Cooper, B., \& Dunne, M. (2005). Anyone for tennis? Social class differences in childrens' responses to national curriculum mathematics testing. In P. Murphy (Ed.), Learners, learning \& assessment (pp. 305328). London: SAGE Publications Inc.

Cooper, B., \& Harries, T. (2002). Children's responses to contrasting "realistic" mathematics problems: Just how realistic are children ready to be? Educational Studies in Mathematics, 49(1), 1-23.

Cooper, B., \& Harries, T. (2005). Making sense of realistic word problems: Portraying working class "failure" on a division with remainder problem. International Journal of Research \& Method in Education, 28(2), 147-169.

Corbalan, G., Kester, L., \& van Merrienboer, J. (2009). Dynamic task selection: Effects of feedback and learner control on efficiency and motivation. Learning and Instruction, 19(6), 455-465.

Cummins, J. (1984). Bilingualism and special education: Issues in assessment and pedagogy. San Diego: College Hill Press.

Cummins, J. (2000). Language, power and pedagogy: Bilingual children in the crossfire. Clevedon: Multilingual Matters.

Dumay, X., \& Dupriez, V. (2007). Accounting for class effect using the TIMSS 2003 eighth-grade database: Net effect of group composition, net effect of class process, and joint effect. School Effectiveness and School Improvement, 18(4), 383-408.

Gibbons, P. (2002). Scaffolding language, scaffolding learning: Teaching second language learners in the mainstream classroom. Portsmouth: Heinemann.

Goldstein-Kyaga, K. (1995). Pizzabagare eller pilot? Om studievalet bland ungdomar i multietniska skolor [Pizza maker or pilot? About study choice among young people in multiethnic schools]. Stockholm: HLS.

Gustafsson, J. E. (1998). Social background and teaching factors as determinants of reading achievement at class and individual levels. Journal of Nordic Educational Research, 18(4), 241-250.

Gustafsson, J. E. (2003). What do we know about effects of school resources on educational results? Swedish Economic Policy Review, 10, 77-110.

Gustafsson, J. E. (2006). Lika rättigheter- likvärdig utbildning? [Equal rights-equivalent education?]: Rädda Barnen. Art nr: 3284. Elanders Infologistics Väst AB.

Gustafsson, J. E. (2010). Causal inference in educational effectiveness research: A comparison of three methods to investigate effects of homework on student's achievement. Paper presented at the The second meeting of EARLI SIG 18, Centre for Educational Effectiveness and Evaluation.

Gustafsson, J. E., \& Stahl, P. A. (2005). Using Mplus with streams 3.0. Mölndal: MultivariateWare.

Hansson, Å. (2010). Instructional responsibility in mathematics education: Modelling classroom teaching using Swedish data. Educational Studies in Mathematics, 75(2), 171-189.

Hansson, Å., \& Gustafsson, J. E. (2011). Measurement invariance of socioeconomic status across migrational background. Accepted for publication in Scandinavian Journal of Educational Research.

Hattie, J. (2009). Visible learning. A synthesis of over 800 meta-analyses relating to achievement. New York: Routledge.

Howie, S. (2003). Language and other background factors affecting secondary pupils' performance in Mathematics in South Africa. African Journal of Research in Mathematics, Science and Technology Education, 7, 1-20.

Jäppinen, A. K. (2005). Thinking and content learning of mathematics and science as cognitional development in content and language integrated learning (CLIL): Teaching through a foreign language in Finland. Language and Education, 19(2), 147-168.

Johansson, M. (2006). Teaching mathematics with textbooks: A classroom and curricular perspective. Lulea, Sweden: Luleå University of Technology. 
Kline, R. B. (1998). Principles and practice of structural equation modeling. New York: Guildford Press.

Kling Sackerud, L. A. (2009). Elevers möjligheter att ta ansvar för sitt lärande i matematik: En skolstudie $i$ postmodern tid [Students' opportunities to take responsibility for their learning in mathematics: An educational study in post-modern time]. Umeå: Umeå universitet.

Morgan, C. (2005). Words, definitions and concepts in discourses of mathematics, teaching and learning. Language and Education, 19(2), 102-116.

Morgan, C. (2007). Who is not multilingual now? Educational Studies in Mathematics, 64(2), $239-242$.

Moschkovich, J. (1999). Supporting the participation of English language learners in mathematical discussions. For the Learning of Mathematics, 19(1), 11-19.

Moschkovich, J. (2009). How language and graphs support conversation in a bilingual mathematics classroom. In R. Barwell (Ed.), Multilingualism in mathematics classrooms: Global perspectives (pp. 78-96). Bristol: Multilingual Matters Press.

Mullis, I., Martin, M., \& Foy, P. (2005). IEA's TIMSS 2003 International report on achievement in the mathematics cognitive domains. Findings from a developmental project. Boston: TIMSS \& PIRLS International Study Center, Lynch School of Education, Boston College.

Mullis, I., Martin, M., Gonzalez, E., \& Chrostowski, S. (2004). TIMSS 2003 international mathematics report. Chestnut Hill: TIMSS \& PIRLS International Study Center, Boston College.

Muthén, B. O. (1994). Multilevel covariance structure analysis. Sociological Methods \& Research, 22, 376398.

Muthén, B. O., \& Muthén, L. K. (1998-2004). Mplus user's guide (3rd ed.). Los Angeles: Muthén \& Muthén.

Oakes, J. (1998). Tracking, detracking, and the politics of educational reform: A sociological perspective. In C. A. Torres \& T. R. Mitchell (Eds.), Sociology of education: Emerging perspectives. New York: State University of New York Press, Albany.

Österlind, E. (1998). Disciplinering via frihet: Elevers planering av sitt eget arbete [Disciplining through freedom: Students planning their own work] (Vol. 75). Uppsala: Acta Universitatis Upsaliensis.

Seidel, T., \& Shavelson, R. J. (2007). Teaching effectiveness research in the past decade: The role of theory and research design in disentangling meta-analysis results. Review of Educational Research, 77(4), 454499.

Setati, M., \& Adler, J. (2000). Between languages and discourses: Language practices in primary multilingual mathematics classrooms in South Africa. Educational Studies in Mathematics, 43(3), 243-269.

Sirin, S. R. (2005). Socioeconomic status and academic achievement: A meta-analytic review of research. Review of Educational Research, 75(3), 417-453.

Skolverket. (2004). Elever med utländsk bakgrund [Student with foreign background]. Stockholm: Skolverket.

Skolverket. (2009). Vad påverkar resultaten i svensk grundskola? Kunskapsöversikt om betydelsen av olika faktorer [[What affects the results of the Swedish compulsory school? Systematic review of the importance of various factors]. Stockholm: Skolverket.

Solano-Flores, G., \& Li, M. (2009). Language variation and score variation in the testing of english language learners, native Spanish speakers. Educational Assessment, 14(3-4), 180-194.

Szulkin, R., \& Jonsson, J. (2007). Ethnic segregation and educational outcomes in Swedish comprehensive schools. Working paper. Stockholm: Swedish Institute of Social Research and Dept. of Sociology.

Tolmie, A. K., Topping, K. J., Christie, D., Donaldson, C., Howe, C., Jessiman, E., et al. (2010). Social effects of collaborative learning in primary schools. Learning and Instruction, 20(3), 177-191.

Tymms, P. (2004). Effect sizes in multilevel models. In I. Schagen \& K. Elliot (Eds.), But what does it mean? The use of effect sizes in educational research (pp. 55-66). London: National Foundation for Educational Research.

Vinterek, M. (2006). Individualisering $i$ ett skolsammanhang [Individaulization in a school context]. Stockholm: Myndigheten för skolutveckling, forskning i fokus, nr 31. Liber.

Vygotskij, L. (1926/1997). The collected works of L.S. Vygotsky. Vol. 3: Problems of the theory and history of psychology. In R. W. Rieber \& J. Wollock (Eds.), The collected works of L.S. Vygotsky. Vol. 3: Problems of the theory and history of psychology. New York and London: Plenum Press.

Vygotskij, L. (1978). Mind in society: The development of higher psychological processes. Cambridge: Harvard University Press.

Vygotskij, L. (1986). Thought and language. Cambridge: Harvard University Press.

Yang, Y., \& Gustafsson, J. (2004). Measuring socioeconomic status at individual and collective levels. Educational Research and Evaluation, 10(3), 259-288.

Zimmer, R. W., \& Toma, E. F. (2000). Peer effects in private and public schools across countries. Journal of Policy Analysis and Management, 19(1), 75-92. 